\title{
INVISIBILIDAD METROPOLITANA Y DERECHOS HUMANOS: EL DEVELAR URBANO DE LOS DESAPARECIDOS POLÍTICOS
}

\section{Invisibilidade metropolitana e direitos humanos: o revelar urbano dos desaparecidos políticos}

Héctor Atilio Poggiese Professor Ttitular da Facultad Latinoamericana de Ciencias Sociales hpoggiese@ flacso.org.ar

Artigo recebido em 30/09/2014 e aceito para publicação em 27/11/2014

http://dx.doi.org/10.12957/tamoios.2014.13079

Resumen Es extensa cualquier lista de invisibilidades en la ciudad metropolitana. En el presente trabajo explicaremos, analizando en el proceso histórico más reciente de Argentina, como la lucha y la política pública de DDHH en la cuestión de los desaparecidos por la última dictadura, ha producido impactos importantes en la ciudad metropolitana (Buenos Aires y el conurbano bonaerense), haciendo visible, tanto en la ciudad material como en lo urbano -entendido en tanto espacio público relacional-, lo que había sido invisibilizado.

Palabras-clave: Derechos Humanos; Invisibilidad Urbana; Política de Estado; Relaciones Estado Sociedade; Transformación Urbana.

Resumo É extensa a lista de invisibilidades em qualquer cidade metropolitana. No presente trabalho explicaremos, analisando no processo histórico mais recente da Argentina, como a luta e a política públcia de DDHH na questão dos desaparecidos pela última ditadura, teve impactos significativos na cidade metropolitana (Buenos Aires e na conturbação de Buenos Aires), tornando visível, tanto na cidade material como no urbano - entendido enquanto espaço público urbano relacional - o que havia sido invisíbilizado.

Palavras-chave: Direitos Humanos; Invisibilidade Urbana; Política de Estado; Relações Estado Sociedade; Transformação Urbana. 


\section{INTRODUCCION}

La antítesis entre lo invisible y lo visible en las metrópolis es un fenómeno dinámico, reversible, tensionado, es siempre un terreno de disputa de los unos (clases, grupos, fragmentos, actores poderosos, intereses) que pujan por imponer su hegemonía y los otros (clases, grupos, fragmentos, débiles, lentos, insurgentes) que pujan por sostener su contra-hegemonía.

Ana Clara Torres Ribeiro es, tal vez, quien con más intensidad ha estudiado y señalado los campos alternos de esa disputa. En sus escritos apela de forma constante, en reflexiones teóricas apoyadas en su visión de la experiencia urbana real, a develar lo oculto, todo lo que se esconde intencionadamente. Practicó siempre el anti-ocultismo, el esclarecimiento de lo que se guarda a cuatro llaves.

En apenas dos páginas de un texto suyo, subtitulado "Pesquisa urbana: local y lugar" (1) trata tres invisibilidades:

Primero, la del hombre lento:

"Existe uma vida de relaçoes, de difícil percepçao, que adquire forma propositiva frente aos limites da democracia formal (formalizada) e a destruiçao das esperanzas de integraçaso social. Nesta vida subterránes e sustantiva, o homen lento (categoría filosófica criada por Milton Santos) que é o homen dos espaços opacos da cidade- cria formas alternativas de socialidade e taticas de sobrevivencia," (la negrita no está en el original)

Enseguida, denunciar que el concepto de ciudad fantasma intenta ocultar otros espacios públicos alternativos:

"Verifica-se a continua criaçao de novos espaços públicos provisórios...en contraste com os espaços alisados, clean, da cidade corporativa...É com base na observaçao de esses processos que se pode afirmar que a hipótese de cidade fantasma, que resultarìa da difusao da TICs, é falsa" (la negrita no está en el original)

Al final, nos avisa que lo local, sobredeterminado por proyectos realizados por actores de escalas poderosas de la realidad social. Acaba disimulando o borrando el lugar, donde anidan otras formas de poder:

“O local é sobre-determinado por constituir o locus de realizaçao de projetos definidos por atores de outras escalas de realidade social. No en tanto, o local no esgota o contexto. Este é tambem lugar, isto é a especialidades da açao espontánea, do inesperado do acaso, do nao-planejado, das experiencias incertas...opoe-se ao pensamento único...é...vida social, memoria coletiva, 
sociabilidade e açao espontánea”. (la negrita no está en el original)

Lo local, subsumiendo el lugar, la contra hegemonía; el hombre lento, opacada, ignorado en la transformación de la ciudad; la ciudad fantasma, virtual, sustituyendo la ciudad de las interrelaciones directas, presenciales. En cada par de estas alternancias Torres Ribeiro descubre el juego perverso de invisibilidad-visibilidad.

Hay otro concepto, el de no-ciudad, derivado del no-lugar que rozaría la idea de invisibilidad por repetición monótona. Habría que descartarlo. Delgado entiende que no oculta sino que complementa a la ciudad. Este autor cuestiona la mala reputación del concepto de no-ciudad derivado de la concepción también negativa del concepto de no-lugar de Augé, para quien son "...lugares de anonimato,... sin identidad ni memoria", pero propone que el no-lugar y por extensión la no-ciudad sean asociados al lugar y a la ciudad como posibilidad o como potencia, porque no son su contracara, ni su lado oscuro o su cara oculta.

Es extensa cualquier lista de invisibilidades en la ciudad metropolitana (los extranjeros, los africanos descendientes, el hábitat de los sin techo, los barrios carenciados, las opciones sexuales, los desplazados, los que viven en las calles, la discriminación racial, la discriminación social)

En el presente trabajo explicaremos, analizando en el proceso histórico más reciente de Argentina, como la lucha y la politica pública de DDHH en la cuestión de los desaparecidos por la última dictadura, ha producido impactos importantes en la ciudad metropolitana (Buenos Aires y el conurbano bonaerense), haciendo visible, tanto en la ciudad material como en lo urbano -entendido en tanto espacio público relacional-, lo que había sido invisibilizado.

Abarcaremos un período de casi 4 décadas, los 38 años que van de 1976 a 2014, con la idea de comparar la situación de los DDHH circunscriptos a las personas desaparecidas, más estrictamente denominados detenidos-desaparecidos. Podemos distinguir -en ese lapso- tramos de contextos políticos diferenciados, en principio la dictadura militar y luego las tres décadas de la recuperación democrática, dentro de la cual identificaremos variaciones importantes de la acción estatal, así como encuentros y desencuentros con los movimientos sociales.

\section{6-1983 LA DICTADURA CÍVICO MILITAR}

En torno a la categoría de "desaparecido" se trabó un debate sordo y limitado a número y extensión, restricto a los familiares y amigos del desaparecido, debate que no pudo expandirse a la consideración pública por el control de los medios que ejercía la dictadura militar, aun para con los medios que eran sus socios o simpatizantes.

Había un pacto secreto entre los responsables del régimen militar en el sentido de negar toda y cualquier acusación sobre el sistema represivo que detenía y hacía desaparecer, cotidianamente, decenas de personas a las que sospechaban de pertenecer a organizaciones políticas o revolucionarias 
o militarizadas, aunque bastaba cualquier supuesto o dato recogido en sus múltiples allanamientos con los que asolaban a la sociedad nacional.

Es cierto que en la ciudad de Buenos Aires y en el gran Buenos Aires (los municipios del conurbano bonaerense que sumados a la Capital Federal conforman lo que podemos reconocer como Área Metropolitana) la presencia militar era ostensible e innegable: los cargos y edificios públicos, la vigilancia en las calles, las constantes "blits" en el tránsito, la censura en los medios gráficos, radiales y televisivos. El poder militar desde el Estado era visible, perceptible para cualquiera.

\section{Invisibilidad del Terrorismo de Estado}

Pero la acción represiva, despiadada, inhumana, del terrorismo de Estado era camuflada, a escondidas, evitaba dejar marcas y testigos: los cuerpos de los detenidos (vivos o muertos) no estaban en ningún lugar, desaparecían. La invisibilidad de esa estrategia de exterminio se aseguraba por los Centros Clandestinos de Detención y el discurso político público de la dictadura.

\section{La red de centros clandestinos de detención}

Este sistema conformó el subsuelo tenebroso donde depositaban, torturaban y circulaban los detenidos. Una estructura urbana clandestina de cárceles improvisadas, maquilladas para no parecerlo, con funciones `parecidas y complementarias.

En el mapa que presentamos en la página siguiente, vemos la localización de dichos centros clandestinos en el área metropolitana de Buenos Aires. Su número (más de 160 sitios) y su distribución territorial extendida en todos los municipios, así como su distancia y densidad son por demás elocuentes para evidenciar una infraestructura gigantesca, capaz de competir con las de otros servicios urbanos, disimulada dentro de la gran ciudad. El destino final de las victimas eran sepulturas de $\mathrm{NN}$ en los cementerios municipales o fosas comunes en lugares ignotos, o los "vuelos de la muerte" lanzando los cuerpos desde aviones al Río de La Plata. 


\section{MAPA DOS CENTROS CLANDESTINOS DE DETENCION}
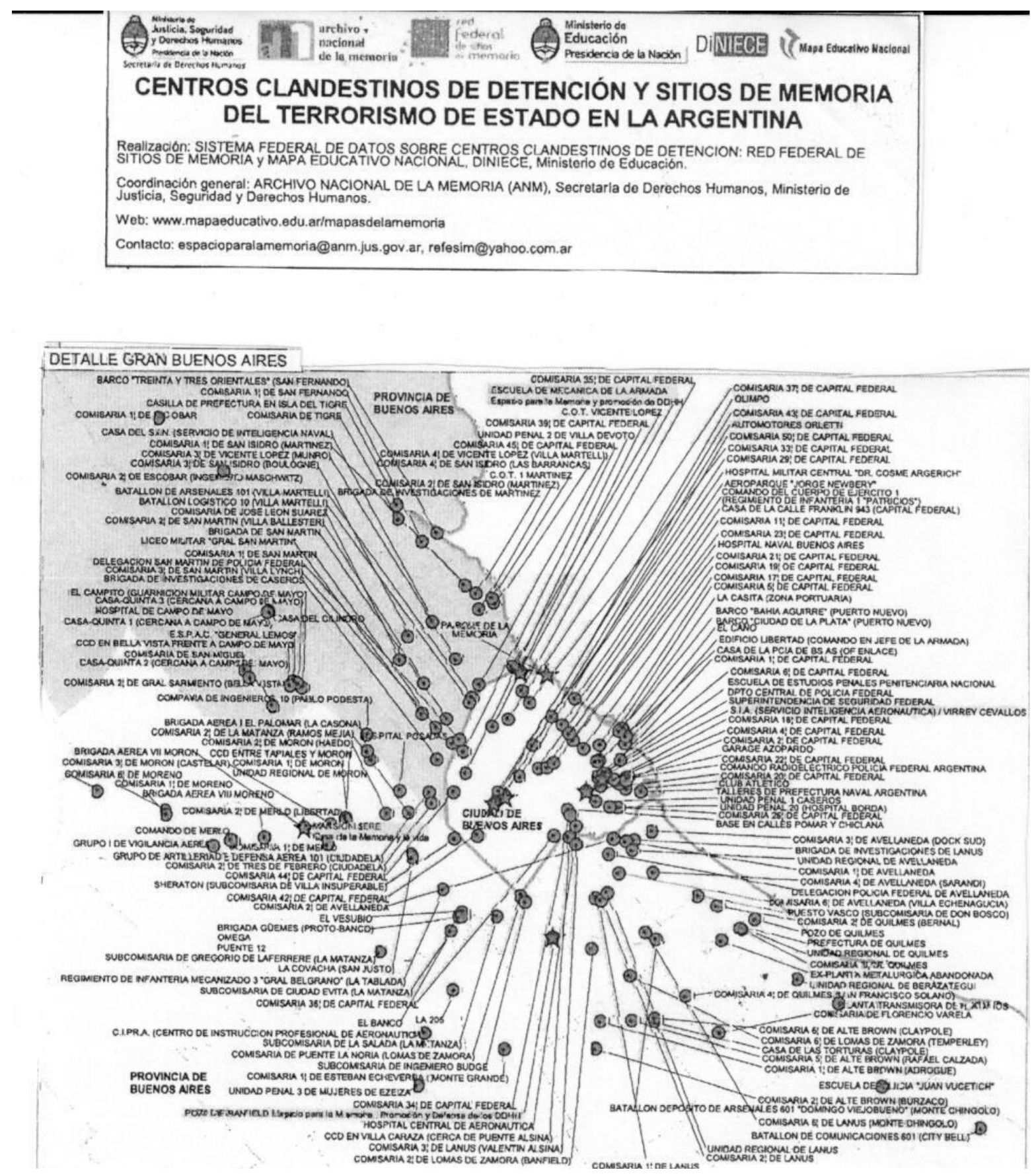

\section{El discurso político público de la dictadura}

Mientras tanto, desde los más altos cargos se descalificaba las denuncias de los familiares argumentando que los tales "desaparecidos" en verdad se escondían, o viviendo en el exterior, servían a una campaña de desprestigio del gobierno militar. Se hablaba de algo que no existía, que era pura invención de los "enemigos de la nación". Por cadena nacional el general Videla, presidente de la junta militar, dio una conferencia especial para referirse al tema y deshacerse de cualquier responsabilidad al respecto. Ante la presencia de organizaciones internacionales de DDHH que, 
haciéndose eco de las aquellas denuncias llegaron a Argentina para investigarlas, desde el Estado se les respondió con la campaña publicitaria "los argentinos somos derechos y humanos". Esa campaña contó con un innegable apoyo en buena parte de la población para quienes tales atrocidades no eran visibles o resultaban silenciadas y disimuladas por la acción comunicadora del régimen. Previo a su final, la dictadura intentó prolongar el ocultamiento al sancionar una ley de auto amnistía para cubrir cualquier defección que el sistema utilizado pudiera filtrar una vez que abandonasen el poder.

\section{ESFUERZOS SOCIALES PARA HACER VISIBLE LA REPRESION}

\section{Madres y Abuelas de Plaza de Mayo}

Las madres de los detenidos-desaparecidos y las abuelas de niños nacidos en cautiverio que tampoco aparecían, mujeres que fueron conociéndose mientras recorrían oficinas gubernamentales, cuarteles militares, cárceles, hospitales, buscando a hijos y nietos secuestrados, pasaron a organizarse en movimientos de reclamación que se transformaron, con el correr de los años en el paradigma social de la lucha por los DDHH: Madres de Plaza de Mayo y Abuelas de Plaza de Mayo. Cuando se juntaban en esa plaza para reclamar las fuerzas policiales las obligaban a circular porque no se permitía a los ciudadanos reunirse en sitios públicos. Así pasaron a caminar incesantemente, sin detenerse, en grupo y conversando, práctica que, sumada al pañuelo blanco en sus cabezas, pasó a ser símbolo conocido a nivel mundial.

Los desaparecidos, miles de personas que eran ocultadas y no reconocidas por la dictadura militar (2), se corporizaban, adquirían alguna visibilidad, por la acción de un movimiento social impensado e inimaginable por los represores. Las Madres, que sufrieron también secuestros y desapariciones, tuvieron apoyo por parte de las organizaciones de defensa de los DDHH preexistentes en el país.

\section{Caracterización sintética de la etapa}

El periodo dictatorial se caracterizó por una acción estatal contundente, sin fisuras ni contradicciones, destinada a ocultar la represión oficial clandestina, sostenida en una extensa infraestructura urbana física fija (los centros clandestinos de detención y sepulturas desconocidas) y móvil (los grupos de tareas de las FFAA), una red encubierta y protegida, creada para negar a los desaparecidos. En contrario la visibilidad, también en sitio urbano, estuvo a cargo de las madres y las abuelas, caminando en torno a la pirámide central de la histórica Plaza de Mayo.

Buenos Aires era en ese tiempo como Moriana, una de las ciudades que narra Italo Calvino 
“...Moriana, con las puertas de alabastro transparentes a la luz del sol, los frontones con incrustaciones de piedra serpentina...si no es el primer viaje, el hombre sabe ya que ciudades como esta tienen su reverso: basta recorrer un semicírculo y será visible la faz oculta de Moriana, una extensión de metal oxidado...ejes erizados de clavos, caños negros de hollín, montones de latas, muros ciegos con inscripciones desteñidas...cuerdas buenas solo para colgarse de una viga podrida...Consiste solo en un anverso y un reverso, como una hoja de papel, con una figura de este lado y otra del otro, que no pueden despegarse ni mirarse".(3)

Una cara de esta ciudad oculta su otra cara, no deja mirarla, la esconde. Con las baldosas se puede dar vuelta esa hoja de papel y hacer patente el reverso, que se pretende permanezca encubierto.

Abordaremos un período de casi 4 décadas, los 38 años que van de 1976 a 2014, con la idea de comparar la situación de los DDHH circunscriptos a las personas desaparecidas, más estrictamente denominados detenidos-desaparecidos. Podemos distinguir -en ese lapso- tramos de contextos políticos diferenciados, en principio la dictadura militar y luego las tres décadas de la recuperación democrática, dentro de la cual identificaremos variaciones importantes de la acción estatal, así como encuentros y desencuentros con los movimientos sociales.

\section{1983-1989 EL GOBIERNO DE ALFONSIN}

Hacia 1982 el movimiento de DDHH colocó la violación a estos derechos en el centro de la oposición a la dictadura, exigiendo el pronunciamiento de los políticos sobre lo acontecido y su investigación por una comisión parlamentaria bicameral que después se trasladara a la Justicia. La mayoría de los políticos repudió la ley de auto anmistía. Fue cuestionada la pretensión militar de legitimar su accionar como una "guerra justa" contra la "subversión" y se rechazó que todos los desaparecidos estuvieran "muertos" como lo decretaba el "Informe Final" de la junta militar presididada por el general Bignone.

En 1983, en la campaña electoral, Alfonsín (luego elegido presidente) resignificó -a su modola consigna "por el derecho a la vida" de las Madres de Plaza de Mayo y le imprimió mayor fuerza evocativa con el lema: "somos la vida". El pasado tendría que saldarse, bajo el imperio de la ley, a través de controversias judiciales. 


\section{VISIBILIDAD DESDE EL ESTADO}

\section{La CONADEP}

El estado democrático, bajo el gobierno de Alfonsín (4) abrió una ventana a la visibilización de los desaparecidos creando la CONADEP (Comisión Nacional sobre la Desaparición de Personas) para investigar lo acontecido con las víctimas

Esta Comisión generó un informe que desbordó los límites previstos. Los "notables" que la integraban fueron escucha para el horror de los testimonios, junto con el reclamo de la intervención de la justicia civil, excediendo el hipotético autojuzgamiento militar con el que el alfonsinismo había pretendido encarar la concreción de su "somos la vida". (5)

\section{El juicio a las juntas}

El gobierno de la UCR creyó posible reintegrar las instituciones castrenses a la sociedad, al mismo tiempo en que los militares inculpados se exponían a los juicios, distinguiendo entre hombres e instituciones. En el llamado "Juicio a las Juntas" no se juzgó en verdad a ninguna junta, sino a nueve hombres que -por el puesto que ocupaban- eran en persona responsables de delitos, pero no comprometían a las FFAA. Fracasó allí la estrategia de la fiscalía orientada a reconocer la existencia de un plan represivo global practicado en conjunto, lo que hubiese obligado a juzgar a las Juntas, no a sus miembros.

Aun así, en 1984 la sociedad argentina, ahora en su mayoría dispuesta a entender, tomó conciencia cabal de lo ocurrido, por la "prueba" judicial. En el Juicio a las Juntas, el rigor de los procedimientos y el decir de los testigos, adquiere cuerpo la categoría jurídica de lo criminal y lo aberrante, cargos por los que resultaron condenados los ex-integrantes de las Juntas Militares.

\section{INVISIBILIDAD DESDE EL ESTADO}

\section{La ventana estatal se entrecierra}

El "Nunca Más" y el Juicio a las Juntas abrieron vías para continuar el enjuiciamiento a los muchos otros culpables, complicando la estrategia del gobierno y del partido-movimiento que manejaba el Estado, quienes esperaban cerrar la cuestión en ese punto, presionados por su propia ambigüedad, por buena parte de la oposición partidaria y gremial peronista y por el poder corporativo empresario agroindustrial.

Aquí se nota el primer impulso del gobierno de Alfonsín para congelar la acción jurídica y se produce un cambio de marco político-ideológico, en la secuencia instrucciones a los fiscales $\rightarrow$ punto 
final $\rightarrow$ obediencia debida

Las "instrucciones del procurador" (febrero de 1987) que definieron límites para impedir la proliferación de juicios a los militares de diverso rango implicados en delitos aberrantes y la ley de Punto Final, que prohibió nuevos juicios, son pruebas de ese cambio. Y la inmediatamente posterior Ley de Obediencia Debida que evita el procesamiento de quienes hubiesen violado DDHH cumpliendo órdenes superiores, completa el cambio básico de configuración política: un auténtico “quiebre ético-social” absolutamente diferente respecto de las bases de legitimidad de 1983.

En los sucesos de Pascuas de 1987, por la sublevación militar de los "carapintadas", están varias de las claves de un nuevo panorama que habrían de constituir un verdadero retroceso del Estado en las secuencias de invisibilización y visibilización respecto de la violación sistemática y planificada de los DDHH durante la dictadura cívico-militar-eclesiástica.

El ex-teniente coronel Rico, jefe de los carapintadas, lo repitió toda vez que pudo su exigencia de que fuera reconocido que el problema militar era político y que, por lo tanto, su solución habría de ser política.

El presidente Alfonsín fue acentuando cada vez más su idea de cerrar el tema militar (juicios) e integrar definitivamente a las FFAA al proceso institucional. Poco a poco desapareció de sus discursos la temática de los derechos humanos reemplazada por el imperativo de la reconciliación. La "cuestión" pasa a definirse y tratarse sólo en términos de "problema militar".

\section{VISIBILIDAD DESDE EL MOVIMIENTO SOCIAL}

\section{Las Madres de Plaza de Mayo y los organismos de DDHH}

En 1987 nos encontramos frente a un cambio de paradigma en el tratamiento del problema: del espacio jurídico se pasa a la "solución política". Si en 1983, al asumir Raúl Alfonsín, los DDHH aparecían como el fundamento moral de la democracia y el juicio a sus violaciones era lo que marcaba su diferencia con el pasado, en cuatro escasos años de un mismo gobierno estos juicios se presentaban como el "obstáculo" para el fin deseado: la integración de las FFAA ¿Cómo podía sostenerse la legitimidad de la búsqueda de la vigencia de los DDHH caso la significación que las FFAA daban al pasado tenebroso lograba imponerse? ¿Cómo podía "integrarse" a una democracia en expansión un sector cuya versión del pasado fuera totalmente impermeable a lo probado sobradamente por la "Justicia"?

La verdad sobre lo acontecido, sostenida con obstinación en la política por el accionar épico de las Madres, las Abuelas y los diversos organismos de DDHH, impedía los diversos intentos de "cierres" que se ensayaban. Se dirá que siempre existe un hiato entre lo "sabido" y lo "juzgable", entre esto y lo que se consigue llegar a juzgar, y entre todo esto y lo posible de ser "probado" (9). Pero suspendido el procedimiento del juicio público y desacreditada la veracidad de lo sostenido por unos 
políticos posibilistas más el totum de aquellos militares cerrados en su autodefensa ¿no se acabaría por negar la real existencia de los hechos ya probados? ¿Es a esa verdad a la que había que renunciar, tal como sucedió en España durante décadas tras el pacto de la Moncloa? La demanda de reconocimiento que el rústico Aldo Rico sostuvo con su motín de la Semana Santa de 1987, al implicar el reclamo de una "solución política" y no judicial, adquirió así su sentido primordial. Si el Estado no usa su capacidad y su (relativo) poder, la invisibilización del crimen y del horror vuelve a primar sobre los intentos orientados a develar y juzgar lo sucedido

\section{CARACTERIZACION DE LA ETAPA}

Los intentos estatales de visibilidad de los desaparecidos, aunque limitados a responsabilidades personales de los autores de las violaciones, fueron al principio bastante firmes (la CONADEP, el Juicio a las Juntas) por la vía judicial. Después se transformó en un solución política transaccional inclinada a una reintegración entre las instituciones armadas y la sociedad (el punto final y la obediencia debida), para al final diluir/desdibujar, dentro del discurso oficial, la temática de los DDHH. Madres, Abuelas y organizaciones de DDHH se mantuvieron firmes en la búsqueda de la verdad, confirmada en los juicios y las condenas, aumentando su reconocimiento político y social.

\section{9-2002 LOS GOBIERNOS DE MENEM, DE LA RUA y DUHALDE}

\section{EL ESTADO PROPONE CERRAR LAS CORTINAS}

Carlos Menem se hizo cargo del gobierno argentino seis meses antes de la fecha indicada. Las elecciones nacionales se hicieron muy temprano y el gobierno de Alfonsín, en medio de un golpe ecónómico de los sectores más concentrados de la economía, una disparada en los precios de los productos de primera necesidad y el crecimiento vertiginoso de la inflación, negoció con Menem (7), ahora presidente electo, que asumiera el poder con esa anticipación.

$\mathrm{Si}$ durante la gestión alfonsinista la acción estatal con respecto a los DDHH y los desaparecidos había sido cimbreante, ambigua, indecisa, nada contundente, para Menem la cuestión no tenía vueltas. Se propuso cerrar todas las puertas para una revisión del pasado reciente y cualquier juzgamiento adicional a sus responsables, dictando de inmediato, en 1989 y 1990, durante su primer año de mandato, las leyes que indultaron a los militares condenados en los juicios a las Juntas que había realizado Alfonsín y también una amnistía general a los delitos sobre los DDHH de aquella época dictatorial.

Sólo habían pasado los primeros tres meses de su presidencia cuando, de improviso, comunicó la firma de varios decretos indultando a militares y algunos civiles. Indultó a todos los jefes militares procesados que no habían sido beneficiados por las leyes de Punto Final y Obediencia Debida, 
promulgadas durante la presidencia de Ricardo Alfonsín en 1986 y 1987. Explicó que “...el indulto es...para que empecemos a reconstruir la patria en paz, en libertad y en justicia..." porque ya era “...tiempo de reconciliación”. La tímida, inconsistente y al final intencionalmente debilitada política de DDHH de Alfonsín se disolvió en un brevísimo tiempo.

La amnistía se extendió, en total, a 220 militares y 70 civiles. El indulto alcanzó a los exmiembros de las Juntas de Comandantes condenados en 1985. Jorge Rafael Videla, Emilio Massera, Orlando Ramón Agosti, Roberto Viola y Armando Lambruschini. Benefició a civiles, algunos de los grupos guerrilleros (incluyendo a personas muertas o desaparecidas), a militares uruguayos, a militares argentinos carapintadas de Semana Santa y Monte Caseros en 1987 y de Villa Martelli en 1988, a otros ex-miembros de la Junta de Comandantes, Leopoldo Galtieri, Jorge Isaac Anaya y Basilio Lami Dozo que fueran condenados por delitos cometidos en la conducción de la guerra de las Malvinas.

Antes de las elecciones Menem se cansó de negar que fuera a dictar una amnistía o indultar a quienes hubieran violado los derechos humanos. El ordenamiento jurídico argentino protegía los derechos humanos por la adhesión nacional al Pacto Internacional de Derechos Civiles y Políticos y a la Convención Internacional contra la Tortura y fue en ese año 1989 que se aprueba la Convención Internacional de los Derechos del Niño. Esos tratados internacionales no permiten amnistiar a quienes cometen delitos de lesa humanidad. La mayoría de la población deseaba que el presidente Carlos Menem se hiciera cargo de su palabra y cumpliera con la promesa electoral de "respetar las sentencias judiciales e impedir que la impunidad se adueñara de la Argentina”. La promesa electoral poco duró y de nuevo el Estado Nacional, igual que en el período de la dictadura, y ahora con el argumento nada ético(8) de la reconciliación, ponía el velo de ocultamiento a la indagación sobre el destino de los desaparecidos, con la intención de invisibilizar de una manera definitiva lo sucedido con aquellos treinta mil secuestrados. Se retornaba a la concepción militar expresada por el entonces presidente de la Junta, general Videla:

“...¿Qué es un desaparecido? En cuanto éste como tal, es una incógnita el desaparecido. Si reapareciera tendría un tratamiento $\mathrm{X}$, y si la desaparición se convirtiera en certeza de su fallecimiento tendría un tratamiento Z. Pero mientras sea desaparecido no puede tener ningún tratamiento especial, es una incógnita, es un desaparecido, no tiene entidad, no está, ni muerto ni vivo, está desaparecido..." (9)

Menem intentó poner en el mercado inmobiliario el predio de la ESMA, principal centro clandestino de detención de la dictadura militar: con esa medida liquidada dos problemas de una sola vez: borraba la memoria física del mayor centro de tortura y muerte y hacía un negocio sideral, porque esas 17 hectáreas están en la zona con el mayor precio del suelo urbano de toda el área metropolitana de Buenos Aires. 


\section{LA SOCIEDAD NO ACEPTA LA OSCURIDAD}

El indulto, sin embargo, generó reacciones multitudinarias en la calle, denuncias de los organismos de DDHH y demandas en la justicia por inconstitucionalidad de esos decretos. Todos alegando que los crímenes de lesa humanidad eran imprescriptibles y no podían ser amnistiados. Fue masiva la movilización promovida por las Madres de Plaza Mayo y por las Abuelas de Plaza de Mayo, que se repitió de forma creciente año a año durante la década que gobernó Menem. En las sucesivas marchas comenzaron a aparecer carteles indicando, en segmentos del mapa de la ciudad y el área metropolitana, los domicilios de los torturadores indultados y liberados por aquellos decretos.

Mas adelante surgieron los llamados "eschaches" (10): organizadas por H.I.J.O.S., nueva organización donde se agrupaban los hijos de los desaparecidos, se trataba de movilizaciones callejeras efectuadas en los barrios y frente a los domicilios de aquellos torturadores que habían sido indultados o amnistiados. El objetivo era hacer conocer a la vecindad la moralidad y responsabilidad penal de los criminales.

Un diario nacional, Página 12, fue el único que se sumó a dar visibilidad al tema de los desaparecidos. Desde su primera edición hasta el presente, todos los días, publica en forma gratuita, recuadros en páginas importantes con las denuncias de familiares y amigos, fotografías y datos del día y lugar de su secuestro o detención.

Ni el gobierno de De la Rua (11), de 1999 a 2001, ni el de Duhalde (12), de 2002 al 2003, modificaron en nada la situación heredada del menemismo y por eso no hubo ningún cambio en el accionar estatal respecto a los desaparecidos. Creció sí la movilización social y el activismo de los movimientos de DDHH, nació el teatro por la identidad y otras expresiones culturales donde iría sedimentando el tema de los desaparecidos, así como la búsqueda de los niños robados iba saldando con la aparición de nietos que recuperaban su identidad. La acción política oficial intentando opacar el conflicto, la acción social encendida en una lucha por hacerlo perceptible.

Mientras tanto, en vigencia otra ley de la época de la dictadura militar, la 8912 de la Provincia de Buenos Aires, favorecía la multiplicación de los privilegiados barrios cerrados que extendían la urbanización para las clases media y alta, en cotos privados. La fragmentación y elitización social se extendía en la superficie urbana, mientras se prolongaba el ocultamiento -en el mismo territorio- de la barbarie de lesa humanidad con los cuerpos de los desaparecidos y sus centros clandestinos de detención.

\section{3-2014 NESTOR KIRCHNER-CRISTINA FERNANDEZ DE KIRCHNER}

\section{PRIORIDAD EN LA AGENDA ESTATAL}

La deuda del Estado Nacional respecto de los desaparecidos comenzó a ser saldada desde el 
Poder Ejecutivo del Estado, un presidente de la Nación, Néstor Kirchner (13) resuelve tomar un conjunto de decisiones que colocaron la política de DDHH en el máximo nivel de prioridad, a) En su discurso de asunción como Presidente Nestor Kirchner se reconoció "parte de la generación diezmada" y se comprometió a que el Estado asumiría sus responsabilidades en los DDHH; b) A pedido del presidente de la Nación el Congreso nacional dictó el 2 de septiembre de 2003 la Ley 25779, que declaró "insanablemente nulas" a las leyes de Punto Final y de Obediencia Debida sancionadas en 1989. Esta iniciativa fue después corroborada por la Corte Suprema de Justicia que el 14 de junio de 2005, declaró la inconstitucionalidad de las leyes mencionadas anteriormente, ratificando la validez de la ley 25779 que las anulaba; c) El 24 de marzo de 2004 hubo dos episodios políticos categóricos: KIrchner ordenó al Jefe del Ejército retirar los cuadros de los miembros de las Juntas de Comandantes de la dictadura de la Galería de Presidentes de la Casa Rosada (sede del gobierno nacional) y abrió la ESMA para su recuperación por los organismos de DDHH con un acto y discurso donde pidió perdón, desde el Estado Nacional, por las atrocidades cometidas por Estado Terrorista.

Después otras decisiones oficiales acompañaron la impronta presidencial:

La Corte Suprema de Justicia, en 2005, declaró la inconstitucionalidad de las Leyes de Punto Final y Obediencia Debida y en el mismo fallo ratificó la ley del Congreso que las declaró nulas, en 2003.

En la Justicia Federal comenzaron desde 2006 los juicios que desde hace más de siete años culminan casi invariablemente con la condena de los responsables de la masacre más grande siglo XX en la Argentina.

En diciembre de 2006, acompañando los juicios orales a los represores, nace un nuevo movimiento social, Barrios X la Memoria y Justicia, integrado por activistas de los DDHH, vecinos, familiares y amigos de desaparecidos, con la finalidad de hacer evidente en la escala de los transeúntes, los lugares donde fueron capturados (o donde vivían o trabajaban), colocando en las veredas de esos barrios baldosas recordatorias.

En 2008 la Corte Suprema da Justicia reconoce la obligación de realizar el análisis de ADN en juicios de identidad y convalida el allanamiento judicial para obtener las muestras necesarias. En ese mismo año se crea en el Ministerio de Justicia, Secretaría de DDHH, una oficina estatal, la Unidad Especial para la Búsqueda de Personas y un fondo de recompensas para datos de personas que el poder judicial busca por delitos de Lesa humanidad. Todavía, en 2013, se establece una recompensa para localizar niños (hoy adultos) apropiados durante la dictadura. Este intenso, concentrado, núcleo de decisiones legales está destinado a acelerar la identificación de los autores de los crímenes y a la recuperación de su identidad de aquellos que, siendo niños, fueron robados a sus padres y apropiados por terceros 


\section{MASIVIDAD DE LA MOVILIZACION SOCIAL}

La movilización social por los DDHH se ha transformado en masiva en este último periodo, así como, de manera constante, se ha diversificado la acción social en múltiples variantes y nuevas organizaciones

Durante esta década fue legislado como feriado nacional el día del golpe militar que dio lugar a la última dictadura. Los 24 de Marzo pasaron a ser el DIA DE LA MEMORIA con la finalidad de dar lugar a que expresen en todas las formas las movilizaciones populares que reivindican los DDHH y condenan al golpe militar. El día de la memoria es una jornada de afirmación y prácticas democráticas. Un aspecto a destacar: al ser cada vez más claro y entendido que la acción estatal habilitaba, con sus decisiones, la libertad de expresión en el tema de los DDH, las marchas que ya eran tradición y venían realizándose desde los 90 fueran adquiriendo una masividad inusitada. Multitudes de cientos de miles se vuelcan a las calles en todo el país en un espectáculo emocional y emocionante, multicolor y plural, con ribetes políticos, culturales y sociales combinados

\section{La opinión de un periodista analiza ese fenómeno:}

"La llama no se apagó con las leyes de la impunidad o los indultos. La creatividad jurídica de los organismos encontró hendijas. Los casos de los nietos apropiados fueron un ejemplo cabal. La reapertura de los juicios a los genocidas no fue un fenómeno aislado. Su proyección trascendió las paredes de los edificios de los tribunales. Claro que fue en ese escenario institucional donde las víctimas recobraron la voz y la autoestima. Fueron testigos de cargo, sus recuerdos se admitieron como pruebas concluyentes. La sociedad democrática les reconoció entidad y credibilidad. En el pasado les pesaba o dolía hablar: la culpa los asediaba, eventualmente las sospechas de quienes habían sido sus compañeros. Una prensa despiadada, aliada objetivamente con los represores, cumplió un rol en esa tarea destructiva. Los años recientes fueron reparadores para los familiares de los compañeros detenidos desaparecidos, para las víctimas sobrevivientes, para los hijos y los nietos.” Mario Wainfeld, diario Pagina12, 06/08/14)

En 2006, en medio del periodo reparador al que alude el periodista citado, nace otro movimiento social, con el nombre de Baldosas por la Memoria, que se desarrolla en diversos barrios de Buenos Aires y el conurbano bonaerense con la finalidad de colocar baldosas en las veredas de la ciudad, en aquellos puntos donde fueran detenidos los después desaparecidos 


\section{IMBRICACIONES ESTADO Y SOCIEDAD}

La novedad de esta etapa es la aparición de relaciones colaborativas entre las iniciativas gubernamentales y las de los movimientos sociales, impulsando acciones asociadas que forman parte de la política pública de DDHH. En particular en el diseño, reglamento e institucionalización de centros, parques y museos de memoria y cultura, llegando en algunos casos a modelos de gestión conjunta, pero también en los archivos de la memoria y campañas publicitarias.

El ejemplo paradigmático es el Espacio Memoria y Derechos Humanos Funciona en el predio, de 17 hectáreas, de la ex ESMA (Escuela de Mecánica de la Armada), que fuera el Centro Clandestino de Detención, Tortura y Exterminio (CCDTyE) de mayor importancia en la dictadura cívico militar de 1976 a 1983. La Armada lo puso al servicio de la actividad represiva para concentrar, torturar y exterminar a miles de detenidos, la gran mayoría todavía desaparecidos.

El ex Casino de Oficiales fue declarado Monumento Histórico Nacional en 2008. Este edificio que fue la base operativa de toda la represión, constituye un testimonio material de los crímenes cometidos, algunos ya condenados y otros juzgados en la actualidad. Más de 120.000 visitantes han realizado las visitas guiadas a este sitio.

En otros edificios de ese espacio funcionan un grupo de centros e instituciones (estatales y sociales) de DDHH, congregando varios miles de personas en sus actividades:

-Archivo Nacional de la Memoria

-Canal Encuentro

-Casa de la Militancia H.I.J.O.S Hijos e Hijas por la Identidad y la Justicia contra el Olvido y el Silencio

-Casa por la identidad

-Centro Cultural de la Memoria Haroldo Conti

-Centro Internacional de Educación en Derechos Humanos de la UNESCO

-Espacio Cultural Nuestros Hijos (EcuNHi)/Asociación Madres de Plaza de /Mayo

-Familiares de Desaparecidos y Detenidos por Razones Políticas

-Iniciativa Latinoamericana Identificación de Personas Desaparecidas (ILID).

-Instituto de Políticas Públicas de Derechos Humanos del MERCOSUR

-Madres de Plaza de Mayo Línea Fundadora

-Memoria Abierta

Repasando el abanico de organizaciones encontramos, en un único sitio, la síntesis donde se refleja la historia de la lucha por los DDHH y se exhibe el grado de madurez alcanzado en las relaciones estado-sociedad. 


\section{AL FINAL, ASOCIACION DE MAXIMA TRANSPARENCIA}

\section{LECTURA DEL GRÁFICO}

Para arrimar algunas conclusiones que esta presentación pudiera alumbrar, es útil una lectura del gráfico (14) que acompaña este título final (ver en la página siguiente).

Veamos entonces.

El tema del gráfico es el los detenidos desaparecidos y la ciudad metropolitana.

El gráfico es un espacio dividido en dos campos, el de la invisibilidad y el de la visibilidad.

El gráfico contiene también una secuencia, una línea de tiempo que clasifica los sucesos para cada etapa del proceso político institucional de los (casi) últimos cuarenta años de la Argentina, designando cada etapa con la simple identificación del tramo histórico y la referencia a la última dictadura cívico militar y a los presidentes que la sucedieron en el período democrático inmediato.

En la columna correspondiente a cada etapa se registran las acciones estatales, sociales o mixtas que en ese período se tomaron, se organizaron o sucedieron, para hacer invisibles o visibles a los desaparecidos.

GRAFICO

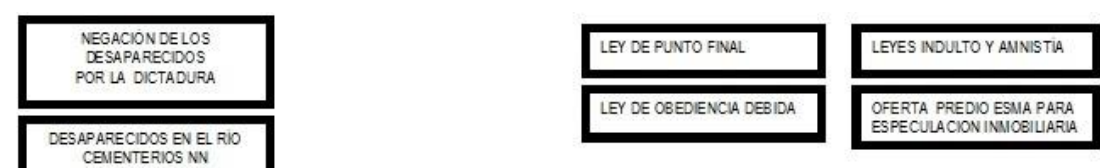
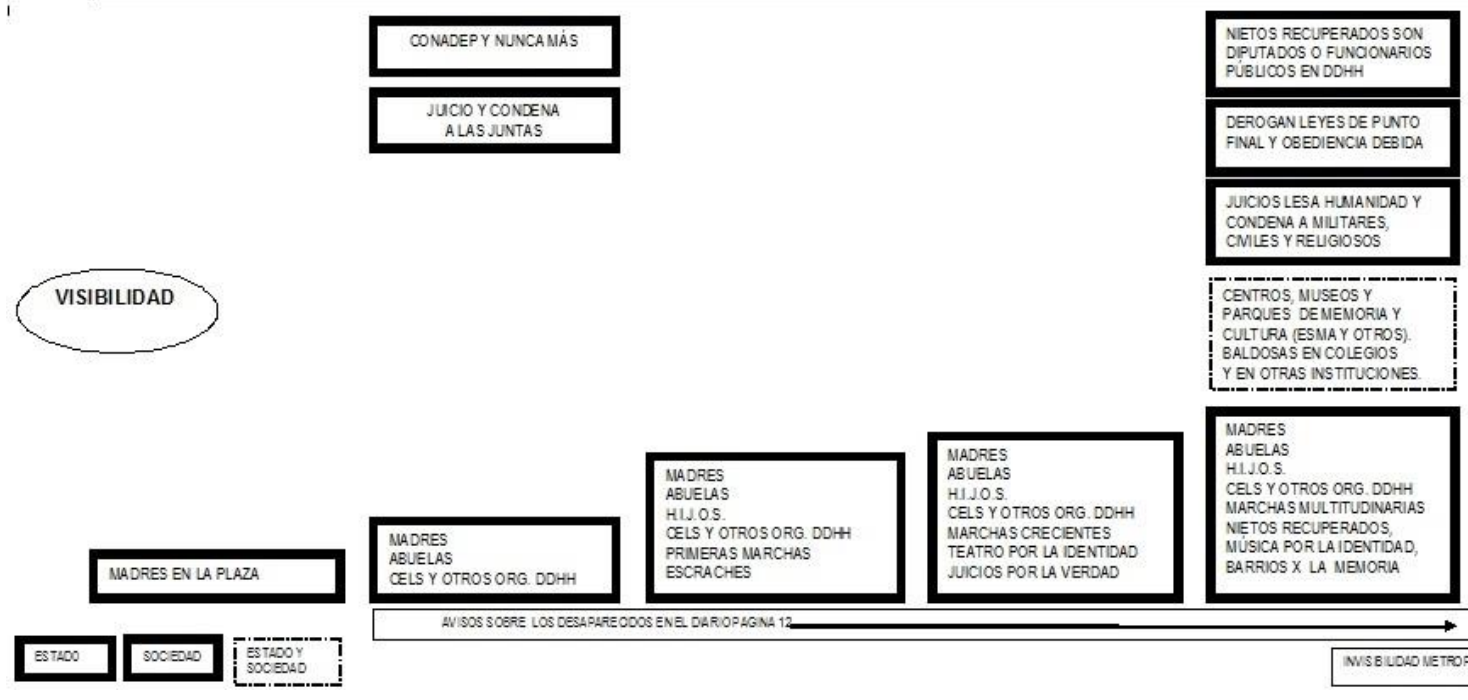
El gráfico nos puede conducir a lecturas variadas:

a) La invisibilidad mayor se localiza en el período de la dictadura militar y la visibilidad mayor en el período democrático de 2003-2014

b) En el lapso intermedio las acciones estatales fluctuan: inicialmente tienden a dar alguna visibilidad a los crímenes producidos desde el estado (informe NUNCA MAS y juicio a las Juntas) para retroceder y retornar a una política de ocultamiento (leyes de punto final, obediencia debida, indulto, amnistía).

c) Las acciones desde la sociedad para hacer visibles los crímenes presentan un crescendo continuo que atraviesa todo el período aumentando el número de organizaciones específicas, concentradas en la búsqueda de los desaparecidos (Madres, Abuelas, HIJOS) y de acciones de desenmascaramiento (escraches, teatro por la identidad, juicios por la verdad, música por la identidad, baldosas por la memoria)

d) La última etapa se caracteriza porque los espacios ocultos e invisibilizados (los Centros de Clandestinos de Detención) son recuperados y transformados en espacios públicos, adquiriendo su valor urbano como sedes de socialibilidad mientras la movilización social se perpetua hasta reconstruir las historias de vida y crear las señales en la ciudad, de los lugares donde vivieron, estudiaron, trabajaron, donde fueron detenidos o asesinados.

e) Esta última etapa se diferencia además, de las otras, porque no solo concentra las acciones estatales y sociales coincidiendo en aumentar la máximo la visibilidad del pasado y recolocarla en el presente, también porque por primera vez en las tres décadas de democracia recuperada, ambos (estado y sociedad), comparten y hasta se asocian de manera formal para instalar y acciones de políticas públicas y para crear y llevar adelante instituciones que programan y gestionan esos lugares reinstalados como espacios públicos

f) Por último en el gráfico se hace evidente que al haberse constituido la política de DDHH como prioritaria de la acción estatal y ser localizada como prioritaria en la agenda pública, la potencia de la asociación estado y sociedad fue suficientemente fuerte para dar vuelta la hora de papel (la ciudad Moriana, de Italo Calvino, antes citada) y, no apenas mostrar el reverso oculto sino encastrarlo en ciudad real, renacido por la relación humana que construye lo urbano, dándole vida a la ciudad.

Por todo eso la ciudad metropolitana resulta hoy cruzada, en la vida urbana de sus espacios públicos, por itinerarios de Memoria Verdad y Justicia.

Se hace Justicia. Varios cientos de militares, responsables de los delitos de lesa humanidad, junto con algunos religiosos y civiles, ya han sido condenados a prisión. El general Videla, jefe de la primera junta del régimen militar, murió en cárcel común, condenado por su responsabilidad máxima en el plan de secuestro de bebés. Otros están siendo juzgados en tribunales en todo el país.

Se sucede, indetenible, la reconstrucción de la Verdad: los testimonios de quienes fueron sobrevivientes y testigos salen a la luz pública, llegan a los medios de comunicación, circulan por las redes virtuales, se acogen en libros y otras publicaciones, se constituyen en cátedras universitarias, en 
contenidos en los colegios secundarios, en la materia de la investigación académica.

Como reseña el gráfico, los juicios están abiertos y las condenas continuarán, alcanzando a los responsables de los vejámenes, las muertes, las desapariciones. Los bebés robados, nietos que recuperaron su identidad son ya 115 y varios de ellos tienen responsabilidades públicas, electos o designados. Aquí hay justicia y recuperación de identidades

Pero, en paralelo, la Memoria es simbolizada, en la ciudad metropolitana, por cambios evidentes: la red de centros clandestinos de detención es hoy una red de centros culturales, lugares de debate democrático, parques o museos de memoria, sitios de intercambios y encuentros, plenos de actividades y de nucleamiento de personas y organizaciones.

La historia urbana tiene vericuetos porque es en si un cruzamiento de variables impensadas, el resultado de una construcción social colectiva, plena de intercambios y vicisitudes en las relaciones personales y organizacionales, verdadera simiente para la creación y recreación de movimientos sociales.

Uno de los movimientos creados más recientemente es el de los grupos que colocan baldosas en distintos puntos de la ciudad: El movimiento se denomina BALDOSAS X MEMORIA $Y$ JUSTICIA (15) y así explican sus objetivos:

"Porque hacemos las baldosas? Las baldosas son, ante todo, nuestra forma de hacer que el "nunca más" supere una expresión de deseos...supone recuperar la presencia de los compañeros detenidos-desaparecidos o asesinados... que sufrieron todas las negaciones: fueron negados en su condición humana, negados sus cuerpos cuando los asesinaron, negadas, ocultadas o demonizadas, su inserción social, su pertenencia, su militancia, su identidad ideológica...esas negaciones, que son la esencia misma del terrorismo de Estado...

Cada baldosa...se constituye en una "marca" en el espacio urbano...son interferencias visuales en la calle...interactuan con personas, comportamientos y objetos...como mecanismos de concientización política y alteran el discurso hegemónico en el espacio público...” (16)

Se organizan por barrios o grupos de barrios, dependiendo de características sub-regionales en la ciudad y el área metropolitana. Confeccionan la lista de desaparecidos con lugar y fecha del hecho de su detención, o donde estudiaba o trabajaba y conforme van reconstruyendo la historia de vida y contactando con la red de familiares, amigos y compañeros que los conocieron, programan la colocación de la baldosa que lo homenajea y simboliza. Esos familiares, amigos y compañeros participaran en la fabricación artesanal de la baldosa y en los actos públicos (17) de su colocación, allí donde se hacen públicas sus historias de vida, que también son reproducidas en sus libros.(18) 
Un tejido urbano metropolitano que tiene hoy cientos de baldosas que llegarán a ser miles, un recorrido en cambio continuo que atrapa al transeúnte, cualquiera sea su trayecto errante.

\section{FINAL DE LA HISTORIA}

Esta historia nos muestra un hecho final en absoluto contraste con el hecho original. La ciudad metropolitana se ve reconstruida por la conjunción convergente entre la experiencia social y la acción estatal: los subsuelos ocultos para proteger los crímenes y desaparecer las huellas se han transformado en espacios públicos donde transcurre y crece la cultura y la vida democrática y, por las veredas donde anduvieron aquellos desparecidos "hablan" a los transeúntes, "marcan" a los caminantes las señales de su historia escondida.

La lucha y la política sobre los DDHH han posibilitado una experiencia urbana que ha transformado en visible vivo, hecho ciudad, aquello que había sido ideado para ser, siempre, invisible.

\section{NOTAS}

1- Ver Ana Clara Torres Ribeiro "Cartografía da açao social: regiao latino-americana e novo desenvolvimento urbano" en Por una sociología do presente, açao, técnica e espaço. Volume 5, págs 197/198, LETRA CAPITAL:RJ, 2013

2- Las organizaciones de DDHH calculan en 30.000 el número de los desaparecidos.

3- Ver Italo Calvino “Las ciudades invisibles” Minotauro: Buenos Aires, 1984, pág.117

4- Elegido por la UCR (Unión Cívica Radical)

5- En el informe Nunca Más algunas figuras notables de la Argentina como el escritor Ernesto Sábato y la periodista Magdalena Ruiz Guiñazú junto con el fiscal federal Julio Strassera, principal querellante por el Estado del llamado "Juicio a las Juntas", dieron armadura conceptual y jurídica a la teoría de los dos demonios, igualando -en un plano político-moral- a la acción guerrillera con el terrorismo paraestatal, esto es, con quienes habían planeado y ejecutado el terror utilizando sin limitaciones el aparato de un Estado del cual se habían apropiado mediante una violación de la Constitución. Esa teoría fue eliminada en sucesivas ediciones del Nunca Más.

6- "La verdad como tal no es nunca equivalente a lo que resulta como 'prueba' de tal o cual procedimiento.” Eugenio Zaffaroni, miembro de la Corte Suprema de Justicia.

7- Candidato del Frente Justicialista (peronismo y aliados)

8- Un fiscal federal lo denomínó "claudicación ética" y "resabio de la monarquía".

9- Histórica declaración de Videla, transcrita por el diario Clarín el 14 de diciembre de 1979

10- Significativo el uso de la palabra "escrache", que proviene del lunfardo, un lenguaje carcelario, períférico, una jerga popular, "giria" en portugués, de difícil acceso y comprensión para los no implicados en su uso. "Quedé/quedó escrachado" significa "me hace visible" o se descubre, algo que 
se mantiene oculto. Es el flash del fotógrafo que da luz para el retrato.

11- Candidato de la Alianza (UCR+Frente Grande)

12- Del Partido Justicialista, fue elegido por el Congreso Nacional para completar el mandato de De la Rua

13- Candidato por el Frente para la Victoria FPV (peronismo y otros). Cristina Fernández también fue candidata del FPV en las dos elecciones que la eligieron presidenta.

14- El primer borrador de este gráfico fue el guión de este artículo. O sea que el guión, que es un principio, termina siendo el final. ¿Concluimos escribiendo el principio o comenzamos escribiendo el final?

15- Debe leerse BALDOSAS POR MEMORIA Y JUSTICIA

16- Ver Barrios X memoria y justicia, Baldosas III, Bs.As. 2014, pág. 8.

17- En www.memorialmagro.com.ar se encuentran videos, tanto del procedimiento de fabricación de la baldosa, como su colocación en las veredas y el evento público que rodea esa instalación.

18- Han editado tres libros, Baldosas por la Memoria I, II y III (2014), ilustrados en su tapa por la fotografía de su primer baldosa "01-12-06 ANDANDO LOS BARRIOS TRAS LAS HUELLAS DE LOS COMPAÑEROS. QUE LAS VEREDAS POR DONDE TRANSITARON HABLEN DE ELLOS".

\section{BIBLIOGRAFIA}

Barrios X memoria y justicia Baldosas III, Instituto Espacio para la Memoria: Buenos Aires, 2014, 320 páginas

CALVINO, Italo Las ciudades invisibles, 2da. Edición, Minotauro:Buenos Aires, 1984, 175 páginas

DELGADO, Manuel Ciudad líquida, ciudad interrumpida, Editorial Universidad de Antioquia:Medellín, 1999, 180 páginas

Sociedades movedizas, Anagrama:Barcelona, 2007, 277 páginas

POGGIESE, Héctor Atilio "Decifrar o enigma da metrópole com a intenção de produzir transformações". In: Metrópole: governo, sociedade e território, Catia Antonia da Silva et alli (orgs.), DP\&A Editora, Rio de Janeiro, 2006

RIBEIRO, Ana Clara Torres. "Metropole: sentidos de fragmentaçao" in Metropoles entre o global e as experiencias cotidianas, Catia Antonia da Silva et alli organizadoras, FAPERJ/EdUERJ:RJ, 2012, páginas 93-109

"Cartografía da açao social: regiao latino-americana e novo desenvolvimento urbano" in Por una sociología do presente, açao, técnica e espaço, Volume 5, LETRA CAPITAL:RJ, 2013, páginas 179-200

SILVA, Armando. Imaginarios urbanos, Tercer Mundo Editores:Bogotá, 1992, 294 páginas 